\title{
A inclusão da pessoa com deficiência no ensino técnico profissionalizante com o uso da tecnologia assistiva fomentando o trabalho e o crescimento econômico conforme o oitavo objetivo de desenvolvimento sustentável
}

\author{
Andrea Ramos \\ Centro Estadual de Educação Tecnológica, São Paulo, São Paulo, Brasil \\ andrea.ramos2008@gmail.com \\ Roberto Kanaane \\ Centro Estadual de Educação Tecnológica, São Paulo, São Paulo, Brasil \\ kanaanhe@gmail.com
}

DOI: https://doi.org/10.26512/rici.v13.n2.2020.31640

Recebido/Recibido/Received: 2020-01-27

Aceitado/Aceptado/Accepted: 2020-05-18

Resumo: O trabalho apresenta a concepção do docente de educação profissional sobre a inclusão da pessoa com deficiência no ensino técnico profissionalizante de São Paulo com a utilização de tecnologia assistiva. Esta modalidade de ensino possibilita a inclusão do deficiente no mercado de trabalho, fomentando o oitavo objetivo de desenvolvimento sustentável da Agenda 2030 da ONU. O objetivo é investigar a percepção dos docentes, a caracterização da inclusão da pessoa com deficiência e o uso da tecnologia assistiva, contribuindo com o crescimento econômico sustentado, inclusivo e sustentável, emprego pleno, produtivo e trabalho decente para todos conforme a Agenda 2030. A abordagem utilizada caracteriza-se como pesquisa exploratória e bibliográfica, bem como a utilização de questionários como método. Obteve-se como resultado o conhecimento parcial sobre tecnologia assistiva, a falta de conhecimento adequado do termo inclusão. Fundamentada em conceitos de inclusão, na classificação e no uso das tecnologias assistivas na educação, conclui-se que há precariedade de formação e de informação adequada.

Palavras-chave: educação profissional. crescimento inclusivo. crescimento sustentável. inclusão na educação.

The inclusion of people with disabilities in professional technical education with the use of assistive technology promotes work and economic growth according to the eighth goal of sustainable development

Abstract: The work presents the conception of the professional education teacher about the inclusion of the person with disabilities in the technical vocational education of São Paulo with the use of assistive technology. This type of education enables the inclusion of the disabled in the labor market, promoting the eighth sustainable development objective of the UN Agenda 2030. The objective is to investigate the perception of teachers, the characterization of the inclusion of people with disabilities and the use of assistive technology, contributing to sustained, inclusive and sustainable economic growth, full, productive employment and decent work for all in accordance with the 2030 Agenda. The approach 
used is characterized as exploratory and bibliographic research, as well as the use of questionnaires as a method. As a result, partial knowledge about assistive technology was obtained, as well as a lack of adequate knowledge of the term inclusion. Based on concepts of inclusion, classification and use of assistive technologies in education, it is concluded that there is a precariousness of training and adequate information.

Keywords: professional education; inclusive and sustainable growth; inclusion concepts in education.

La inclusión de personas con discapacidad en la educación técnica profesional con el uso de tecnología de asistencia promueve el trabajo y el crecimiento económico de acuerdo con el octavo objetivo del desarrollo sostenible

Resumen: El trabajo presenta la concepción del maestro de educación profesional sobre la inclusión de la persona con discapacidad en la educación técnica profesional de São Paulo con el uso de tecnología de asistencia. Este tipo de educación permite la inclusión de los discapacitados en el mercado laboral, promoviendo el octavo objetivo de desarrollo sostenible de la Agenda 2030 de la ONU. El objetivo es investigar la percepción de los docentes, la caracterización de la inclusión de las personas con discapacidad y el uso de tecnología de asistencia, contribuyendo al crecimiento económico sostenido, inclusivo y sostenible, el empleo pleno y productivo y el trabajo decente para todos de acuerdo con la Agenda 2030. El enfoque utilizado se caracteriza por la investigación exploratoria y bibliográfica, así como el uso de cuestionarios como método. Como resultado, se obtuvo un conocimiento parcial sobre la tecnología de asistencia, así como una falta de conocimiento adecuado del término inclusión. Con base en los conceptos de inclusión, clasificación y uso de tecnologías de asistencia en educación, se concluye que existe una precariedad de la capacitación y la información adecuada.

Palabras clave: educación profesional; crecimiento inclusivo y sostenible; Conceptos de inclusión en la educación.

\section{Introdução}

Segundo o IBGE no último Censo Demográfico em 2010, 45,6 milhões de pessoas declararam ter pelo menos um tipo de deficiência, constituindo $23,9 \%$ da totalidade da população brasileira, sendo 18,60\% deficiência visual, 5,10\% deficiência auditiva, 7\% deficiência motora e 1,40\% deficiência mental ou intelectual, segundo dados divulgados na Cartilha do Censo 2010 - Pessoas com deficiência, correspondendo a aproximadamente 1/4 da população, número relevante de cidadãos que precisam estar incluídos de forma ativa e participativa na sociedade.

Uma das vias para a inclusão desta camada da população é a educação, pois de acordo com Moran (2011, p. 49) "todo desenvolvimento verdadeiramente humano significa o desenvolvimento conjunto das autonomias individuais, das participações comunitárias e do sentimento de pertencer à espécie humana", com a educação é possível potencializar o desenvolvimento da pessoa com deficiência individualmente e consequentemente em ações conjuntas contribuindo com o aprimoramento da sociedade, outra via de inclusão é o trabalho, que possibilita a sobrevivência desta camada da população sem o viés assistencialista e colabora com a autoestima e a reabilitação.

Deste modo, tem-se o ensino técnico profissionalizante como uma alternativa viável à inclusão da pessoa com deficiência, ratificado segundo a pesquisa Educação Profissional e 
Você no Mercado de Trabalho coordenada por Marcelo Neri do Centro de Políticas Sociais da FGV em parceria com o Instituto Votorantim. A probabilidade de uma pessoa conseguir se inserir no mercado de trabalho com formação profissionalizante é $48,2 \%$ maior que de um indivíduo que não possui, elencando a importância desta modalidade de ensino para a da inclusão da pessoa com deficiência.

Ademais, também Valle (2016, p. 17) verifica a importância do:

\begin{abstract}
acesso à educação, compreendido aqui como acesso à aprendizagem, deve ser visto como ferramenta para a efetivação do Direito Fundamental à Educação, além de estar diretamente relacionado à dignidade da pessoa humana, uma vez que ler, escrever, se expressar, contar são ações básicas no cotidiano de qualquer indivíduo e estar à margem dessas ações é encontrar-se em situação indigna e excludente. A ausência de uma escola verdadeiramente inclusiva acaba por excluir parcela da sociedade do direito à educação.
\end{abstract}

De acordo com Mantoan \& Santos (2010, p. 9) "a defesa da inclusão, como uma nova perspectiva educacional nas escolas públicas e privadas, tem como objetivo o acolhimento de todos os alunos em suas especificidades".

Contudo, a história da pessoa com deficiência sempre foi um relato de extermínio, segregação e exclusão, uma vez que segundo Barreto \& Barreto (2014, p. 13) desde o início dos tempos, na época das sociedades primitivas de subsistência - período das cavernas, o indivíduo com deficiência estava a margem da participação comunitária, uma vez que era abandonado a própria sorte para não atrapalhar o grupo, em razão de não conseguir obter alimentos para o grupo em atividades de caça e pesca.

Com o passar dos anos e o desenvolvimento da humanidade, as práticas de extermínio, segregação e exclusão continuam disseminadas pelo mundo, tem-se em Esparta o extermínio dos deficientes, em virtude do pensamento militarista, em Atenas eram segregados, em Roma explorados em shows de entretenimento, e com prostituição.

A evolução da humanidade continua, mas a pessoa com deficiência ainda estava segregada, na Idade Média seguindo os preceitos cristãos da sociedade da época, uma vez que o pensamento da Igreja Católica de que todos os indivíduos foram criados por Deus eles não poderiam ser exterminados, contudo a deficiência era vista como um castigo, desta forma, o indivíduo precisava ser segregado.

Com a saída das trevas do obscurantismo para a luz da ciência, a partir do século XVI mudanças socioculturais fazem com que o deficiente passe a ter locais de atendimento específicos.

No entanto, a ciência continuava a se desenvolver e a Igreja perdia seu poder para a burguesia, o capitalismo alterava as estruturas do mundo e novos valores sociais perpassaram 
os séculos XVIII e XIX, e a pessoa com deficiência passou a ser tratada como um problema da medicina, a pedagogia servia aos propósitos médicos, com grandes avanços da psicologia.

De acordo com Garcia (2010, p.21) com a evolução gradual da humanidade:

a assistência e a qualidade do tratamento dado não só para as pessoas com deficiência como para população em geral tiveram um substancial avanço ao longo do século XX. No caso das pessoas com deficiência, o contato direto com elevados contingentes de indivíduos com sequelas de guerra exigiu uma gama variada de medidas. A atenção às crianças com deficiência também aumentou, com o desenvolvimento de especialidades e programas de reabilitação específicos. É fato notório que nos países europeus do pós II Guerra Mundial formou-se o Estado de Bem-Estar Social, cujos programas e políticas incluíam também pessoas com deficiência, em particular as vítimas ou mutilados de guerra. Mas, já no início do século XX, entre 1902 e 1912, na Europa, existem registros da existência de pelo menos vinte instituições destinadas ao exclusivo atendimento de pessoas que apresentavam algum tipo de deficiência. As primeiras campanhas para arrecadação de fundos e recursos para o auxílio dos portadores de deficiência datam deste período, num movimento associado a campanhas do mesmo tipo voltadas para proteção e atendimento básico de pessoas pobres, idosos ou crianças carentes.

Em nenhum momento o indivíduo com deficiência foi incluído na educação com preocupação em desenvolver suas potencialidades e incluí-lo no mercado de trabalho de forma plena e participativa, ele ficava relegado a ajuda assistencialista e alguns focos de aprendizagem manual para garantir sua sobrevivência.

No Brasil, conforme Jannuzzi (2012, p. 45):

A defesa da educação dos anormais foi feita em virtude da economia dos cofres públicos e dos bolsos dos particulares, pois assim se evitariam manicômios, asilos e penitenciárias, tendo em vista que essas pessoas seriam incorporadas ao trabalho.

Contudo, a humanidade continuava a evoluir, a ciência, os valores, a identidade dos indivíduos foram se tornando cada vez mais fluídas, e deste modo, a pessoa com deficiência foi se integrando a sociedade, ingressando nas escolas, entrando no mercado de trabalho.

Com o ingresso da pessoa com deficiência nas escolas o professor passou a desenvolver um papel fundamental na inclusão, pois são suas estratégias e metodologias que contribuem e auxiliam a desenvolver as potencialidades do deficiente, conforme ratificado por Rodrigues (2008, p. 25) ao afirmar que:

a inclusão tem sido marcada pelo conceito de normalização que implica em oferecer à pessoa com deficiência condições de vida tão normais quanto seja possível para todas as pessoas, isto é, a sociedade deve organizar-se para eliminar barreiras e oferecer condições para que todas as pessoas desenvolvam suas potencialidades. 
Em função do exposto tem-se como problema de pesquisa: Qual a concepção do docente de ensino profissional sobre a inclusão da pessoa com deficiência com o uso de tecnologias assistivas?

O objetivo deste estudo é identificar a visão do docente sobre a inclusão da pessoa com deficiência, no ensino técnico profissionalizante, a partir da utilização das tecnologias assistivas.

\section{Referencial Teórico}

Com base na Declaração Mundial sobre Educação para todos (Conferência de Jomtien) aprovada em 1990, a Declaração de Salamanca, elaborada em 1994, e na Declaração Internacional de Montreal de 2001, todos documentos e resoluções da Organização das Nações Unidas (ONU), tem-se constatado que o Brasil possui uma das leis mais atuais sobre a inclusão da pessoa com deficiência, promulgada em 6 de julho de 2015 com a Lei. 13.146, nomeada como Lei Brasileira de Inclusão da Pessoa com Deficiência, conhecida também como Estatuto da Pessoa com Deficiência.

Tem-se segundo a lei, a caracterização da pessoa com deficiência, em seu 20 artigo (BRASIL, 2015):

considera-se pessoa com deficiência aquela que tem impedimento de longo prazo de natureza física, mental, intelectual ou sensorial, o qual, em interação com uma ou mais barreiras, pode obstruir sua participação plena e efetiva na sociedade em igualdade de condições com as demais pessoas.

Quanto ao tipo as deficiências podem ser caracterizadas como: física, auditiva, visual, mental e múltipla, que se constitui com a associação de mais de uma deficiência.

Após a conceituação do indivíduo e definição da educação como via de inclusão, em razão de "ter um papel fundamental na formação dos indivíduos para exercerem funções no sistema produtivo social" (OLIVEIRA, 2016, p. 125), ressalta-se a importância da educação profissional tecnológica como modalidade de ensino relevante visando garantir a inclusão de pessoas com deficiência no mercado. Ao unir educação e trabalho, tem-se como mecanismo facilitador a inserção, contribuindo para que a pessoa com deficiência tenha sua identidade social, conforme menciona Mendes (2004, p. 106):

através do trabalho o indivíduo com deficiência pode demonstrar suas potencialidades e competências e construir uma vida mais independente e autônoma. Consequentemente, o trabalho exerce também um efeito reabilitador, na medida em que contribui para o aumento da autoestima e nível de ajustamento pessoal. 
Ademais, além da questão da identidade social do trabalhador e da sobrevivência da pessoa com deficiência garantidas pelo emprego, a inclusão da pessoa com deficiência no ensino técnico profissionalizante fomenta o objetivo de desenvolvimento sustentável 8 Trabalho decente e crescimento econômico, a partir de educação de qualidade, e deste modo reduzir as desigualdades, outros objetivos de desenvolvimento sustentáveis (4 e 10) da Agenda 2030 da ONU.

Desta forma, tem-se a relevância da inclusão da pessoa com deficiência na educação, pois segundo Morin (2011, p. 47) "o homem somente se realiza plenamente como ser humano pela cultura e na cultura", uma relação perpassada pelo uso das tecnologias de informação e comunicação (TIC) que abarca a globalização, pela fluidez e rapidez do compartilhamento de informações da contemporaneidade, uma vez que segundo Menino (2014, p. 30) "a informação e o conhecimento passaram a ser elementos primordiais" da civilização.

Outrossim, "a capacitação profissional e o aprendizado tecnológico são mecanismos estratégicos para a inserção do Brasil no cenário econômico internacional" (PETEROSSI, 2014, p. 17).

Deste modo, o docente do ensino técnico profissional torna-se elemento fundamental nesta engrenagem, conforme Mantoan (2015, p. 21-22) ressalta ao afirmar que:

um novo paradigma do conhecimento está emergindo das interfaces e das novas conexões que se formam entre saberes outrora isolados e partidos e dos encontros da subjetividade humana com o cotidiano, o social, o cultural. Redes cada vez mais complexas de relações, geradas pela velocidade das comunicações e informações, estão rompendo as fronteiras das disciplinas e estabelecendo novos marcos de compreensão entre as pessoas e do mundo em que vivemos.

Corroborado por Peterossi (2005, p.104) ao afiançar que:

educar para e com as novas tecnologias de informação e comunicação significa capacitar pessoas com competências cada vez mais sofisticadas para bem avaliar e compreender todos os aspectos da vida em sociedade que afetam as pessoas.

Conforme Calheiros, Mendes e Lourenço (2018, p. 236):

entendemos que as práticas pedagógicas assumidas pelo professor durante o processo de escolarização podem influenciar no aprendizado dos seus estudantes e na construção de um ambiente escolar inclusivo.

Neste novo contexto advindo da globalização surgem então as tecnologias assistivas (TA) visando auxiliar o professor a potencializar a aprendizagem da pessoa com deficiência. 
Segundo a Secretaria Especial dos Direitos Humanos da Presidência da República (BRASIL, 2009):

Tecnologia assistiva é uma área do conhecimento, de característica interdisciplinar, que engloba produtos, recursos, metodologias, estratégias, práticas e serviços que objetivam promover a funcionalidade, relacionada, à atividade e participação de pessoas com deficiência, incapacidades ou mobilidade reduzida, visando sua autonomia, independência, qualidade de vida e inclusão social.

De acordo com Teófilo Galvão Filho (2009) " a expressão "Tecnologia Assistiva" com frequência é utilizada na língua portuguesa ao lado das expressões "Ajudas Técnicas" e "Tecnologias de Apoio" na maioria da vezes como sinônimos", de acordo com a legislação vigente, decreto 5296/2004 consideram-se ajudas técnicas: "os produtos, instrumentos ou tecnologia adaptados ou especialmente projetados para melhorar a funcionalidade da pessoa portadora de deficiência ou com mobilidade reduzida, favorecendo a autonomia pessoal, total ou assistiva".

A tecnologia assistiva ou tecnologias assistivas, conforme o referencial utilizado, compõe-se de uma gama de possibilidades de recursos a serem utilizados para potencializar a aprendizagem da pessoa com deficiência, e segundo Barreto \& Barreto (2014, p. 87) estão inclusos produtos de baixa e alta tecnologia e que são "organizados ou classificados de acordo com os objetivos funcionais a que se destinam".

Tem-se então as seguintes categorias de classificação das tecnologias assistivas segundo Barreto \& Barreto (2014 p. 88 e 93): 1. auxílios para a vida diária e vida prática, 2. auxílios para a comunicação aumentativa e alternativa (CAA); 3 . sistemas de controle de ambiente; 4. projetos arquitetônicos para acessibilidade; 5. órteses e próteses; 6 . adequação postural; 7. auxílios de mobilidade, 8 . auxílios para qualificação da habilidade visual e recursos que ampliam a informação a pessoas com baixa visão ou cegas; 9. auxílios para pessoas com surdez ou com déficit auditivo; 10. mobilidade em veículos; 11. esporte e lazer.

Salienta-se então a importância do conhecimento e da formação do professor no uso das tecnologias assistivas, uma vez que de acordo com Calheiros, Mendes e Lourenço (2018, p. 239):

modelos de formação de professores e dos demais profissionais envolvidos nas diversas ações junto ao público-alvo da Educação Especial devem ser repensados, no intuito de que esses profissionais possam conhecer 0 recurso de TA e fazê-lo atingir o seu objetivo na garantia de ampliação de funcionalidade e participação social do sujeito, por todo o seu curso de vida.

Corroborado por Bersch (2017, p. 12) ao afiançar que a tecnologia assistiva permite "com o objetivo de diversificar e qualificar o acesso ativo dos alunos às informações e 
proporcionar a eles múltiplas formas de organizarem, expressarem e apresentarem os conhecimentos construídos".

\title{
3. Método
}

Atualmente, a inclusão é garantida no mercado de trabalho por lei e este movimento ganha força no Brasil a partir dos anos 1980, em função do Ano Internacional das Pessoas com Deficiência (AIPD) promulgado pela ONU em 1981, e segundo Marta Gil (2012, p. 167):

\begin{abstract}
é possível afirmar que, para garantir o ingresso e o sucesso de jovens e adultos com deficiência no trabalho, de forma digna e respeitando características e necessidades individuais, é preciso que o acesso à qualificação aconteça de forma diferenciada - trazendo o conceito de equiparação de oportunidades para a formação profissional.
\end{abstract}

Deste modo, verifica-se a importância do trabalho diferenciado de inclusão da pessoa com deficiência com o uso consciente da tecnologia assistiva, desenvolvido pelo docente da educação profissional, para caracterizar a pesquisa que possui enfoque qualitativo conforme perspectiva abordada por Sampieri, Collado e Lúcio (2013, p. 36). Fundamenta-se "na compreensão e interpretação dos fenômenos, por meio das percepções e dos significados produzidos pelas experiências dos participantes". Adotou-se a técnica de questionário para coleta de dados e a amostra conceituada como não probabilística por tipicidade, foi estabelecida pela seleção de elementos que o pesquisador considere representativos da população-alvo" de acordo com Vergara (2016), constituindo-se por 18 respondentes, docentes da instituição pesquisada.

O presente estudo possui caráter exploratório, pois, conforme definido por Vergara (2016), trata-se de uma área em que há pouco conhecimento acumulado e sistematizado, mesmo com a promulgação em 1996 da Lei no 9.394 - Diretrizes e Bases da Educação Nacional, com o capítulo III do título IV destinado a "educação profissional integrada às diferentes formas de educação, ao trabalho, à ciência, e à tecnologia" visando "ao permanente desenvolvimento de aptidões para a vida produtiva" (CORDÃO e MORAES, 2017, p.49).

Deste modo, salienta-se a importância do estudo em função da necessidade de produzir conhecimento e disseminá-lo dado o pouco material existente a respeito do tema na contemporaneidade.

O objeto de estudo foi uma instituição de ensino técnico profissionalizante no Estado de São Paulo, criada por decreto-lei em 6 de outubro de 1969, que compõe uma rede com 223 Escolas Técnicas Estaduais distribuídas por 165 municípios paulistas. 
A instituição no segundo semestre de 2018 possuía cerca de 208 mil alunos matriculados nos cursos técnicos e técnico integrado ao médio.

A fundamentação teórica baseou-se em consulta bibliográfica contemplando a análise da importância do uso das tecnologias assistivas e da relevância do ensino técnico profissionalizante no contexto da globalização.

\section{Resultados e Discussão}

Quanto ao resultado da aplicação dos questionários aos docentes do contingente de 18 respostas tem-se que $88,9 \%$ dos docentes do ensino técnico profissionalizante, acreditam que há diferença entre inclusão e integração escolar e 11,1\% discordam, segundo Figura 1.

Figura 1 - Diferença entre Inclusão e Integração Escolar

\section{Há diferença entre inclusão e integração escolar? Total 18}

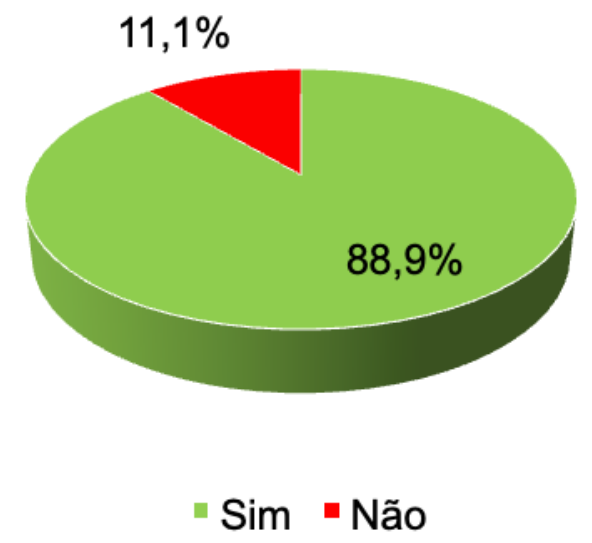

Fonte: Dados de Pesquisa

Em virtude das respostas apresentadas verifica-se o desconhecimento do conceito e da diferença entre inclusão e integração, conforme alguns feedbacks selecionados:

\begin{tabular}{|l|l|}
\hline 1 & Incluir envolve a totalidade. Integrar envolve apenas estar presente \\
\hline 2 & Penso que a integração escolar se refere à todos os estudantes, com ou sem necessidades especiais \\
\hline 3 & $\begin{array}{l}\text { Integração refere-se ao ajuste do aluno no modelo existente. Inclusão e preparar o modelo certo às } \\
\text { necessidades dos alunos }\end{array}$ \\
\hline 4 & Inclusão pressupõe que o indivíduo era excluído, integrar é algo mais sociável, fazer tornar parte. \\
\hline 5 & $\begin{array}{l}\text { Penso que a integração é parte complementar a inclusão. Não basta só 'incluir', mas é necessário } \\
\text { integrar, de fato. }\end{array}$ \\
\hline 6 & Integração significa tratar todos as diferenças de maneira adequada. \\
\hline
\end{tabular}


7 Incluir é por dentro, inserir. Integrar é incluir, mas fazendo com que esse inserido faça parte do todo. Parecem sinônimos, mas não são, apesar de integrar tem que incluir como traço semântico.

8 Integrar o aluno nas atividades, levando em consideração suas limitações, para que ele possa adquirir o conhecimento de maneira adequado, nem que para isso seja necessário utilizar de materiais específicos, interpretes ou auxilio de outro docente. Incluir o aluno nas atividades, coloca ele a par da atividade, mas ele não será ativo no aprendizado

9 Eu sei que há diferença, porém não sei qual é.

Fonte: Dados de Pesquisa

Ao questionar sobre o conhecimento do termo tecnologias assistivas pelo professor, identificou-se que $50 \%$ possuem conhecimento parcial; $27,8 \%$ desconhecem o termo e apenas 22,2\% reúnem conhecimento total quanto às tecnologias assistivas, de acordo com a figura 2.

Figura 2 - Conhecimento do termo Tecnologias Assistivas

\section{Você conhece o termo tecnologias assistivas? Total 18}

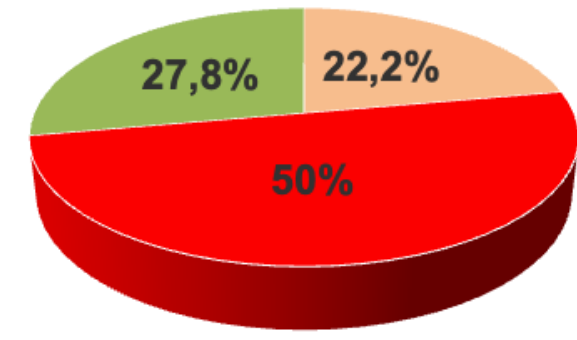

\section{Totalmente - Parcialmente "Desconheço}

Fonte: Dados de Pesquisa

Concomitantemente ao questionar os docentes se ministram ou ministraram aulas para pessoa com deficiência obtém-se o resultado $50 \%$ tanto para aqueles que necessitam aulas ou não, conforme a figura 3. 
Figura 3 - Aulas ministradas para pessoas com deficiência

\section{Você ministra ou ministrou aulas para pessoa com deficiência? \\ Total 18}

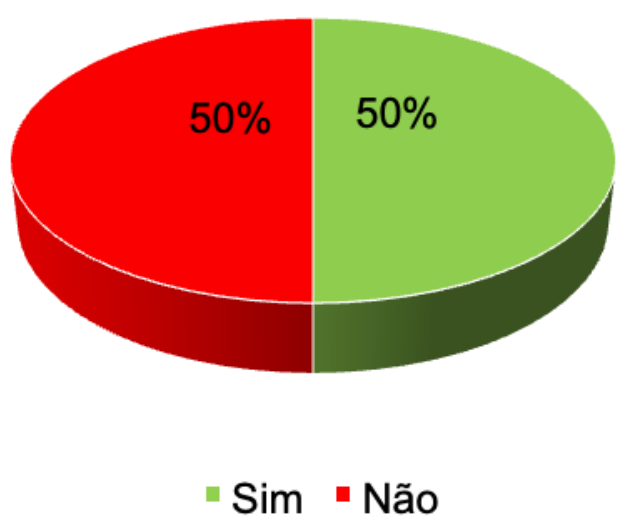

Fonte: Dados de Pesquisa

Figura 4 - Treinamentos para utilização de Tecnologia Assistiva.

\section{A Instituição que você trabalha promove treinamentos para a utilização de tecnologias assistivas em sala de aula? \\ 17 respondentes}

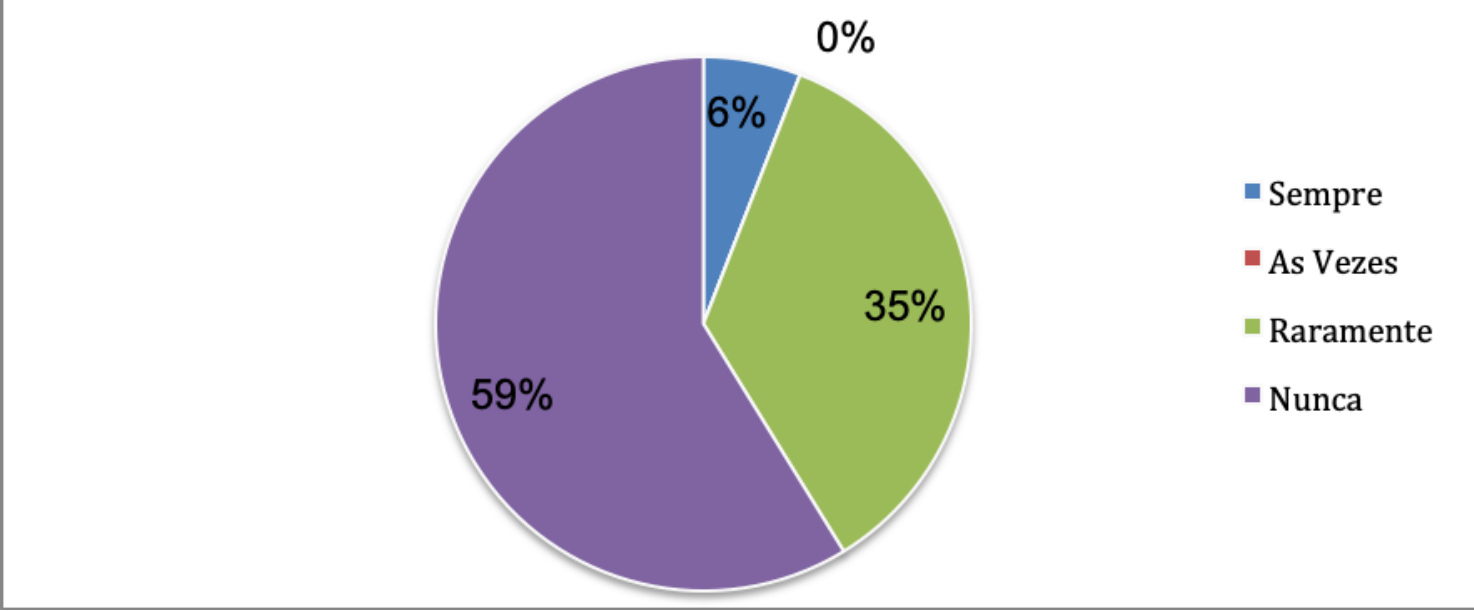

Fonte: Dados de Pesquisa

A partir dos dados da figura 4, tem-se que os docentes desconhecem o conceito e as diferenças entre inclusão e integração, bem como, termo tecnologias assistivas. Identificou-se que, em sua maioria, não participaram de treinamentos sobre a temática, embora já tenham 
ministrado aulas para alunos com deficiência; denota-se, então, a falta de preparo do docente para lidar com a situação de maneira adequada.

Cabe ressaltar segundo Mantoan $(2015$, p. 16) que:

a perspectiva de formar uma nova geração dentro de um projeto educacional inclusivo é fruto do exercício diário da cooperação, da colaboração, da convivência, do reconhecimento e do valor das diferenças, que marcam a multiplicidade, a natureza mutante de todos nós.

\title{
5. Considerações finais
}

Conforme Farias (2015, p. 17) "para entendermos melhor a relação entre a arte de ensinar, a técnica e o trabalho, podemos sintetizar o ensino técnico como a revolução na adequação da educação à tecnologia e à qualificação profissional para o mercado de trabalho", e com o uso das tecnologias assistivas estabelecer como prerrogativa essencial o conceito de que cada deficiência de cada aluno é única, para a escolha da tecnologia ou recurso a ser utilizado. Quanto a utilização da mesma deve-se potencializar o conhecimento e a aprendizagem da pessoa com deficiência, o que poderá auxiliar o professor no desenvolvimento da atividade proposta, conforme Gil $(2005$, p. 53):

\begin{abstract}
quando falamos em tecnologias e recursos que auxiliam a criança ou adolescente com deficiência na sala de aula, devemos lembrar que eles não são recursos que magicamente farão o aluno superar suas dificuldades. Qualquer que seja o auxílio pensado, sempre passa pela percepção que o professor tem sobre as dificuldades e possibilidades de seu aluno. $O$ auxílio só faz sentido a partir desta relação. Por isso, dizemos que não há regras, existem sugestões para ajudar o professor a pensar em possibilidades, mas isto sempre será posterior a este primeiro contato e conhecimento prévio do professor em relação a criança ou adolescente.
\end{abstract}

Cabe ao docente refletir sobre as estratégias e práticas de ensino e aprendizagem utilizadas, uma vez que se constituem como objetos de trabalho dos docentes e objetos de aprendizagem (OA) dos estudantes, pois de acordo com Hummel $(2015$, p.36) "estratégias e práticas fazem parte de sua rotina, porém a falta de conhecimento específico dos recursos inviabiliza o planejamento eficaz para promover momentos de aprendizagem significativa".

Concomitantemente o professor necessita compreender o contexto, analisar a situação de aprendizagem para "atender às singularidades de todos os aprendizes ao mesmo tempo" de acordo com Orrú (2017, p.66), bem como, flexibilizar o currículo para o atendimento de todos os estudantes, uma vez que a educação é um processo dialógico de troca de conhecimentos corroborado por Rodrigues (2016, p.79-80) ao afirmar que:

o fluxo de comunicação permite a troca de saberes e experiências que se acumulam, construindo as competências e habilidades que permitirão aos 
professores e alunos a elaboração de conceitos e práticas pedagógicas que servirão de alicerce para a troca continua de conhecimentos.

Consequentemente, salienta-se a necessidade de uma mudança de postura da sociedade em geral, pois as transformações estão sendo feitas e a inclusão vai se fortalecendo gradativamente. Entretanto, os docentes participantes do estudo estão em descompasso com a velocidade das mudanças e precisam se preparar, conhecer o termo tecnologias assistivas, seu propósito, seus usos e prerrogativas com a finalidade de contribuir para a inclusão da pessoa com deficiência no mercado de trabalho como fomento ao trabalho decente e crescimento econômico. De acordo com o Comitê de Ajudas Técnicas - CAT, instituído pela portaria no 142 de 16 de novembro de 2006. Conforme Sartoretto e Bersch (2019), considera que:

\begin{abstract}
tecnologia assistiva é uma área do conhecimento, de característica interdisciplinar, que engloba produtos, recursos, metodologias, estratégias, práticas e serviços que objetivam promover a funcionalidade, relacionada, à atividade e participação de pessoas com deficiência, incapacidades ou mobilidade reduzida, visando sua autonomia, independência, qualidade de vida e inclusão social.
\end{abstract}

Portanto, verifica-se que o professor necessita conhecer os recursos disponíveis no mercado para potencializar a aprendizagem da pessoa com deficiência. Silva (2014, p. 106) considera que o professor deve identificar as reais necessidades do aluno para utilizar as tecnologias como ferramenta facilitadora da aprendizagem, uma vez que de acordo com Peterossi $(2005$, p.105) "as novas tecnologias estão alterando a natureza do que é preciso aprender, de quem precisa aprender, de quem ensina e do como pode ser ensinado".

Por tratar-se de um estudo preliminar de caráter exploratório, afere-se que o mesmo retrata percepções introdutórias sobre a temática abordada, deste modo, sugere-se a possibilidade de novas pesquisas acadêmicas e estudos sobre os resultados apresentados visando ampliar o escopo e ao mesmo tempo apresentar alternativas de ação/intervenção quanto à utilização de tecnologia assistiva junto as pessoas com deficiência.

\title{
Referências
}

BARRETO, M. A. de O. C; BARRETO, F. de O. C. Educação inclusiva: contexto social e histórico, análise das deficiências e uso das tecnologias no processo de ensino-aprendizagem. São Paulo: Érica, 2014. 178p.

BERSCH, Rita. Introdução à tecnologia assistiva. 2017. 20 p. Disponível em: <http://www.assistiva.com.br/Introducao_Tecnologia_Assistiva.pdf>. Acesso em 16 mar. 2020. 
BRASIL. Decreto no 5296, de 02 de Dezembro de 2004. Disponível em: $<$ http://www.planalto.gov.br/ccivil 03/ ato2004-2006/2004/decreto/d5296.htm> Acesso em 24 set. 2019.

BRASIL. Lei no 9.394 de 20 de Dezembro de 1996 . Disponível em: <http://www.planalto.gov.br/ccivil 03/leis/19394.htm> Acesso em 29 mar. 2019.

BRASIL. Lei $\mathrm{n}^{0}$ 13.146, de 6 de julho de 2015 . Disponível em: <https://www2.camara.leg.br/legin/fed/lei/2015/lei-13146-6-julho-2015-781174publicacaooriginal-147468-pl.html/ >. Acesso em 16 mar. 2020.

BRASIL. Presidência da República. Secretaria dos Direitos Humanos. Cartilha do Censo 2010 Pessoas com Deficiência. Brasília: Secretaria de Direitos Humanos da Presidência da República, Secretaria Nacional de Promoção dos Direitos da Pessoa com Deficiência, Coordenação-Geral do Sistema de Informações sobre a Pessoa com Deficiência. 2012. 36p. Disponível em: $<$ http://www.unievangelica.edu.br/novo/img/nucleo/cartilha-censo-2010-pessoas-comdeficienciareduzido.pdf >. Acesso em 16 mar. 2020.

BRASIL. Subsecretaria Nacional de Promoção dos Direitos da Pessoa com Deficiência. Comitê de Ajudas Técnicas Tecnologia Assistiva. Disponível em: $<$ https://www.mpes.mp.br/Arquivos/Anexos/385c40f5-66aa-42a6-beef-eb7621350f95.pdf $>$. Acesso em 16 mar. 2020.

CALHEIROS, D. dos S; MENDES, E. G; LOURENÇO, G. F. Considerações acerca da tecnologia assistiva no cenário educacional brasileiro. Revista Educação Especial, Santa Maria, v. 31, n. 60, p. 229-244, mar. 2018.2 Disponível em: <https://periodicos.ufsm.br/educacaoespecial/article/view/18825>. Acesso em: 16 mar. 2020.

CORDÃO, F. A; MORAES, F. de. Educação Profissional no Brasil síntese histórica e perspectivas. São Paulo: Editora Senac, 2017. 240p.

FARIAS, E. B. Um olhar para o ensino técnico: o ensino profissionalizante e a educação no Brasil. São Paulo: Porto de Ideias, 2015. 157p.

GALVÃO FILHO, T. A. A Tecnologia Assistiva: de que se trata? In: MACHADO, G. J. C.; SOBRAL, M. N. (Org.). Conexões: educação, comunicação, inclusão e interculturalidade. Porto Alegre: Redes Editora, p. 207-235, 2009. (disponível no formato PDF em: www.galvaofilho.net/assistiva.pdf

GARCIA, V. G. Pessoas com deficiência e o mercado de trabalho: histórico e contexto contemporâneo. 205f. Tese (Doutorado em desenvolvimento econômico). UNICAMP, Campinas, 2010.

GIL, M. Educação inclusiva: o que o professor tem a ver com isso? São Paulo: Imprensa Oficial do Estado de São Paulo, 2005. 168p.

GIL, M. Caminhos da Inclusão. São Paulo: SENAI-SP Editora, 2012. 248p.

HUMMEL, E. I. Tecnologia Assistiva: a inclusão na prática. Curitiba: Appris, 2015. 175p.

IBGE. Pessoas com deficiência: adaptando espaços e atitudes. 2017. Disponível em: $<$ https://agenciadenoticias.ibge.gov.br/agencia-noticias/2012-agencia-de- 
noticias/noticias/16794-pessoas-com-deficiencia-adaptando-espacos-e-atitudes $>$. Acesso em 16 mar. 2020.

JANNUZZI, G. de M. A educação do deficiente no Brasil: dos primórdios ao início do século XXI. 3. ed. rev. Campinas: Autores Associados, 2012. 224p.

MANTOAN, M. T. É. Inclusão escolar - 0 que é? Por quê? Como fazer? São Paulo: Summus, 2015. 50p.

MANTOAN, M. T. E; SANTOS, M. T. T. dos. Atendimento educacional especializado: políticas públicas e gestão nos municípios. São Paulo: Moderna, 2010. 96p.

MENDES, E. G. et al. Estado da arte das pesquisas sobre profissionalização do portador de deficiência. Temas em Psicologia, Ribeirão Preto, v. 12, n. 2, p. 105-118, 2004. Disponível em $<$ http://pepsic.bvsalud.org/scielo.php?script=sci_arttext\&pid=S1413-

389X2004000200003\&lng=pt\&nrm=iso >. Acesso em 16 mar. 2020.

MENINO, S. E. Educação Profissional e Tecnológica na Sociedade do Conhecimento. São Paulo: Centro Estadual de Educação Tecnológica Paula Souza, 2014. (Coleção Fundamentos e Práticas em Educação Profissional e Tecnológica, v.2). 135p.

MORIN, E. Os sete saberes necessários à educação do futuro. 2. ed. São Paulo: Cortez, 2011. $104 p$.

NERI, M. C. A educação profissional e você no mercado de trabalho. Rio de Janeiro: FGV, $2010 . \quad$ Disponível em: <http://portal.mec.gov.br/index.php?option=com_docman\&view=download\&alias=5300eduprofi-texto-neri-20100526-formatado\&category_slug=maio-2010-pdf\&Itemid=30192 >. Acesso em 16 mar. 2020.

OLIVEIRA, I. A. Epistemologia e Educação - Bases Conceituais e Racionalidades Científicas e Históricas. Petrópolis: Vozes, 2016. 136p.

ORRÚ, S. E. O re-inventar da inclusão: os desafios da diferença no processo de ensinar e aprender. Petrópolis: Vozes, 2017. 147p.

PETEROSSI, H. G; MENESES, J. G. de C. Revisitando o saber e o fazer docente. São Paulo: Pioneira Thomson Learning, 2005. 156p.

PETEROSSI, H. G. Subsídios ao estudo da Educação Profissional e Tecnológica. 2. ed. São Paulo: Centro Estadual de Educação Tecnológica Paula Souza, 2014. 80 p. (Coleção Fundamentos e Práticas em Educação Profissional e Tecnológica, v.1).

RODRIGUES, O. M. P. R. Educação especial: história, etiologia, conceitos e legislação vigente, $2008 . \quad$ Disponível em: $<$ https://www.researchgate.net/publication/284714615 EDUCACAO ESPECIAL HISTORIA ETI OLOGIA CONCEITOS E LEGISLACAO VIGENTE/references >. Acesso em 16 de mar. 2020.

RODRIGUES, I. E. Educação Inclusiva: um desafio para o século XXI. Jundiaí: Paco Editorial, 2016. 132p. 
SAMPIERI, H. R.; COLLADO, C. F.; LUCIO M. P.B. Metodologia de Pesquisa. 5. ed. São Paulo: Penso Editora, 2013. 624p.

SARTORETTO, M. L.; BERSCH, R. Assistiva - Tecnologia e Educação. 2019. Disponível em: $<$ https://www.assistiva.com.br/tassistiva.html>. Acesso em 16 mar. 2020.

SASSAKI, R. K. Inclusão construindo uma sociedade para todos. 8. ed. Rio de Janeiro: WVA, 2010. 176p.

SILVA, L. G. dos S.. Educação inclusiva: práticas pedagógicas para uma escola sem exclusões. São Paulo: Paulinas, 2014. 109p.

VALLE, A. de S. V. do. A reinvenção do cotidiano escolar: percepções de docentes de turmas regulares sobre a inclusão. In: RODRIGUES, I. E. (Org.). Educação Inclusiva: Um desafio para o século XXI. Jundiaí: Paco Editorial, 2016. p. 15-31.

VERGARA, S. C. Projetos e Relatórios de Pesquisa em Administração. 16. ed. São Paulo: Atlas, 2016. 104p.

VIEIRA, A. M. D. P; SOUZA JUNIOR, A. de. A educação profissional no Brasil. Revista Interacções, v. 12, n. 40, p.152-169, $2016 . \quad$ Disponível em: <https://revistas.rcaap.pt/interaccoes/article/view/10691 >. Acesso em 16 mar. 2020. 